\title{
Combined mediastinal and retroperitoneal fibrosis
}

\author{
H. W. SALMON \\ From the East Ham Memorial Hospital, London, E.7, and Queen Mary's Hospital for the East End, \\ Stratford, London, E.15
}

A case of combined idiopathic mediastinal fibrosis and retroperitoneal fibrosis is described. It is possibly the twelfth case to be reported during life. A review of the literature reveals the 'ubiquity' of localized collagenosis and the trend of opinion as regards aetiology and treatment.

An example of this rare combination of localized idiopathic fibrosis was reported by Morgan, Loughridge, and Calne (1966a). After much correspondence it was agreed that only 10 or 12 cases had appeared in the literature, two of which were diagnosed during life (Morgan et al., 1966b).

The following case was diagnosed within a week of admission to hospital and the patient is still alive 14 months later.

\section{CASE REPORT}

A Jamaican man, aged 33, married, and an electrician by trade, arrived in England early in 1958. On 18 January 1966 he was referred to Queen Mary's Hospital.

For about 10 weeks he had been complaining of progressive swelling of the face, neck, arms, hands, and chest above the nipple line. $\mathbf{A}$ month before he had attended an ophthalmic hospital on account of soreness of the eyes, lacrimation, and occasional blurring of vision. Drops were prescribed but gave no relief. He also complained of headaches and 'fullness' of the head, especially on bending, dyspnoea, and palpitations on effort with a slight cough. $\mathrm{He}$ is a non-smoker, rarely takes alcohol, and denies taking any drugs. There was no loss of weight or other significant symptoms.

In the past he had had frequent attacks of tonsillitis, torsion of the left testis at age 15, and in September 1958 he underwent an abdominal operation. In other respects his past and family histories were not significant.

Clinical examination revealed slight puffiness of the face, upper chest, and backs of the hands which pitted on pressure. The conjunctivae were suffused. The nails were normal and there were no enlarged glands.

No superficial veins were obvious, doubtless due to his dark skin.

A right paramedian keloid abdominal scar was present and the left testis was atrophic. There was no oedema of the feet.

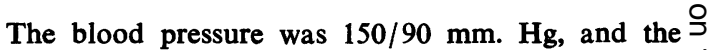
right and left pulses were of equal volume. The urine contained a considerable amount of protein but there were no other significant signs.

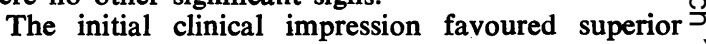
vena caval obstruction or, less likely, the nephrotic $\vec{\bullet}$ syndrome. He was admitted on 27 January 1966 for $\stackrel{\infty}{\infty}$ further investigation.

A radiograph of the chest (Fig. 1) showed widening of the upper mediastinum, humping of the right hemidiaphragm anteriorly, and prominence of the lesser fissure. Haemoglobin was $17.8 \mathrm{~g} . / 100 \mathrm{ml}$., white blood cell count was $4,700 /$ c.mm., and the erythro- $\stackrel{\mathbb{Q}}{\circ}$ cyte sedimentation rate was $5 \mathrm{~mm}$. in the first hour $\overrightarrow{\vec{F}}$ (Westergren). The urine continued to contain much $\frac{3}{3}$ protein, there were no casts but up to 5,000 white cells $/ \mathrm{ml}$. were seen. A 12-hour specimen of urine, volume $480 \mathrm{ml}$., showed no casts, white cells $720,000 /$ $\mathrm{ml}$., and red blood corpuscles $1,840,000 / \mathrm{ml}$.

The blood urea was $47 \mathrm{mg} . / 100 \mathrm{ml}$. and the creatinine clearance was $75 \%$ of normal. The serum $\tilde{x}^{\circ}$ electrolytes were as follows: potassium $4.9 \mathrm{mEq} /$ litre, $\overline{-}$ sodium $137 \mathrm{mEq} /$ litre, and chlorides $102.3 \mathrm{mEq} /$ litre Total serum proteins were $7.8 \mathrm{~g} . / 100 \mathrm{ml}$, albumin $4.5 \%$ g. $/ 100 \mathrm{ml}$., and globulin $3.3 \mathrm{~g} . / 100 \mathrm{ml}$. The electrophoretic strip showed a normal pattern. Serum cholesterol was $293 \mathrm{mg} . / 100 \mathrm{ml}$.

A normal bacterial flora was cultured from a throat swab but the anti-streptolysin titre was raised to $320 \cong$. units $/ \mathrm{ml}$. The electrocardiogram showed non-specific N $\mathrm{T}$-wave changes which later became less pronounced.

Throughout the first week of his admission he N remained afebrile and complained of a pulsating headache. Slight oedema of the upper extremity per- $\omega$ sisted and was most marked in the morning. Proteinuria continued and the urine remained sterile, cons읃 centrated to a specific gravity of 1010 and diluted to 1000. The blood pressure remained at $160 / 110 \mathrm{~mm}$ ? $\mathrm{Hg}$ and the jugular venous pressure was raised.

A presumptive diagnosis of superior vena caval ob-0 struction with some renal tract anomaly was made

Meanwhile the following record of a surgical admis $-\vec{D}$ sion dated October 1958 was discovered: "Admitted ${ }^{\varrho}$ with flatulent dyspepsia, sharp constant pains in the left iliac fossa and right hypochondrium referred too 


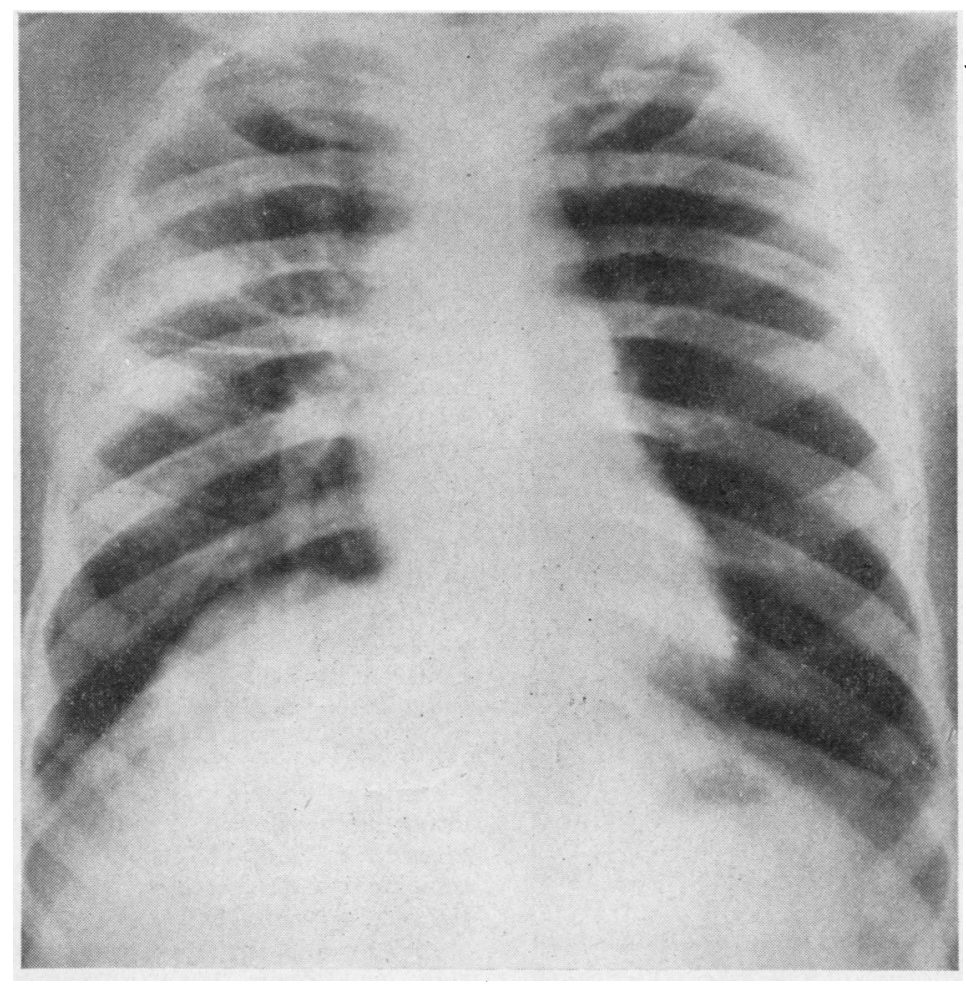

FIG. 1. Radiograph of chest showing widening of superior mediastinum, humping of right hemi-diaphragm, and prominence of the lesser fissure.

the shoulders. Intermittent diarrhoea and colic-temperature $100 \cdot 8^{\circ}$. The white cell count was $10,100 /$ c.mm., the erythrocyte sedimentation rate was $22 \mathrm{~mm}$. in the first hour, and the urine was sterile. An intravenous pyelogram showed no opaque stones but a left-sided hydronephrosis.'

Exploration of the subphrenic spaces by needle was performed and no pus was found. Laparotomy followed and the record states 'Plastic peritonitis all over. Adhesions between stomach, duodenum, and coils of intestine. No tubercle seen. Loculated strawcoloured fluid found in the lower pelvis. Dense adhesions all round caecum and appendix.

'Removal of fluid. Wound closed in layers. No biopsy was taken.

'The patient continued to improve and after a few days' convalescence was sent home. The cause of his symptoms was not definitely established.'

On this evidence a diagnosis of combined mediastinal and retroperitoneal fibrosis appeared reasonable. Therefore an intravenous pyelogram was requested and showed the anticipated distortion of the left ureter towards the inferior vena cava with loss of definition of the lower two-thirds of the right ureter, probably the result of partial obstruction (Fig. 2).
Confirmation of the diagnosis demanded tissue biopsy, but there appeared to be little justification for further laparotomy.

The following pathological reports were received:

Cardiolipin Wassermann and V.D.R.L. tests negative. Sternal marrow biopsy showed normal cytology and no L.E. cells were seen in either marrow or peripheral blood. Serum bilirubin $0.5 \mathrm{mg} . / 100 \mathrm{ml}$. Thymol turbidity 2 units. Zinc sulphate turbidity 8 units. Alkaline phosphatase 7 K.A. units. Aspartate transaminase 20 international units/litre. The histoplasmin complement fixation test was negative.

On 9 March 1966 the patient was transferred to East Ham Memorial Hospital and two days later median sternotomy was performed.

On removal of thymic tissue overlying the left innominate vein a very hard mass of solid white tissue was found obstructing and enfolding the great vessels (Fig. 3). Several pieces of this abnormal tissue were removed for examination by two independent pathologists. A summary of their combined reports is as follows :

'The biopsy specimen was cultured and yielded no growth. Myco. tuberculosis could not be isolated. The specimens consisted of pieces of cellular fibrous tissue 


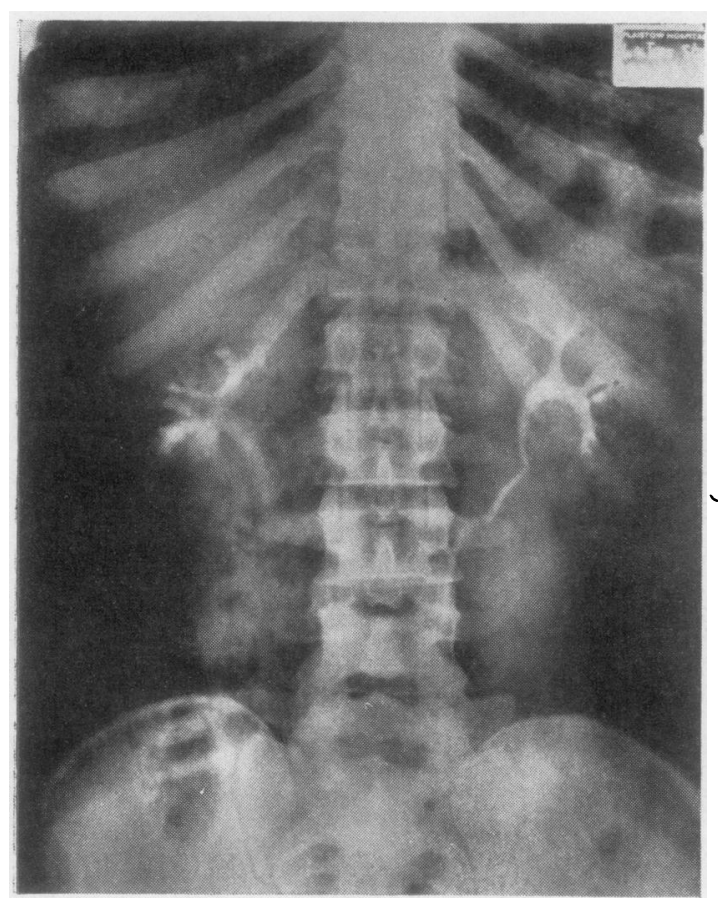

FIG. 2. Intravenous pyelogram showing displacement of the left ureter towards the midline and loss of definition of the lower two-thirds of the right ureter. which is vascular and infiltrated with lymphocytes in $\stackrel{\overrightarrow{\vec{D}}}{\stackrel{\vec{m}}{+}}$ nodular collections and occasional plasma cells. In $\bar{C}$ one specimen small arterioles show occlusion by $\underline{\underline{D}}$ adventitial fibrosis. A few macrophage giant cells $\frac{\bar{\omega}}{5}$ are seen but there is no sign of neoplastic cells or $\vec{\nabla}$ foreign material. Special staining does not show any amyloid, excess reticulin, or parasites. The appear- $\omega$ ances are consistent with idiopathic mediastinal $\overrightarrow{0}$ fibrosis.' (Fig. 4.)

PROGRESS AND TREATMENT For the first few days $\stackrel{\omega}{\sigma}$ after the mediastinal biopsy there was a marked $\vec{x}$ increase in the oedema of the upper extremity and the i left radial pulse was weaker than the right. He was $\omega$ given a five-day course of penicillin, 1 mega-unit ? twice daily, and streptomycin, $0.5 \mathrm{mg}$. twice daily. $\vec{F}$ There was no post-operative fever. On the third post- $\infty$ operative day he was given prednisone, $100 \mathrm{mg}$. daily in divided doses. This was continued for three week s $\vec{r}$ and then slowly reduced until it was finally withdrawn on 14 November 1966.

During the subsequent months he felt rather better $\stackrel{\rho}{\mathcal{S}}$ but objectively there was little change. Short courses $\vec{\varphi}$ of bendrofluazide, $5 \mathrm{mg}$. on alternate mornings, with $\stackrel{\infty}{\circ}$ salt restriction seemed to give him some relief.

Further investigations were carried out when the opportunity allowed. The blood urea showed a progressive fall to $24 \mathrm{mg} . / 100 \mathrm{ml}$. The haemoglobin remained high, between 18.4 and $16.7 \mathrm{~g} . / 100 \mathrm{ml}$. P.C.V. $50 \%$. M.C.H.C. $30 \%$.

In July 1966 he was readmitted for 10 days with $\varrho$ right renal colic, haematuria, and $E$. coli infection which rapidly responded to ampicillin.

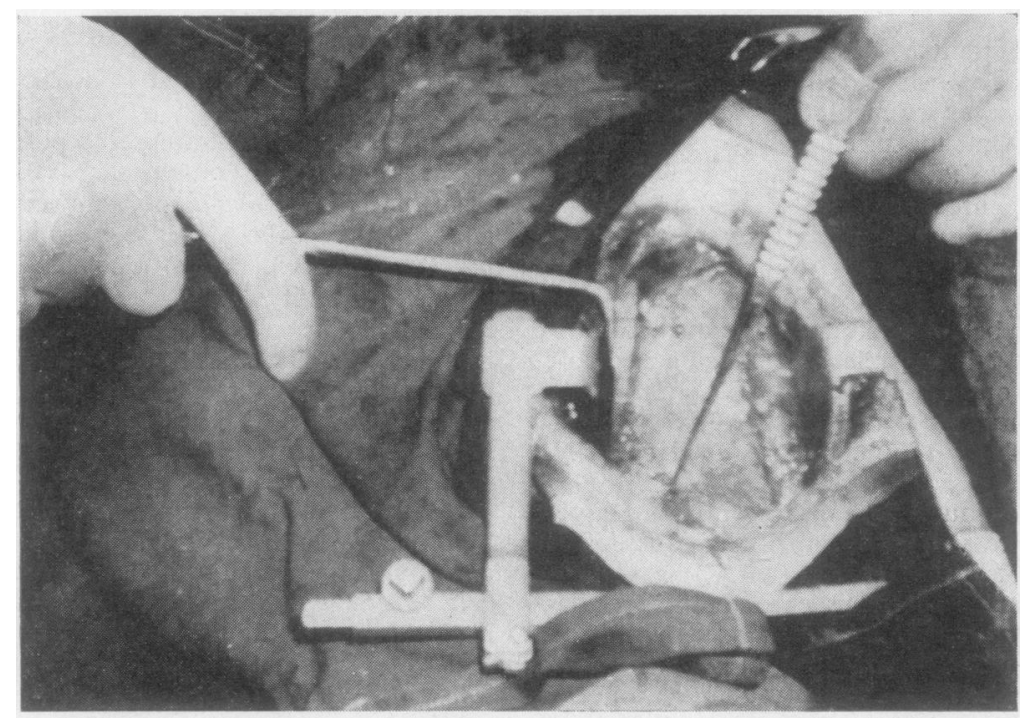

FIG. 3. Median sternotomy revealing a mass of firm white tissue surrounding the great vessels in the superior mediastinum. 


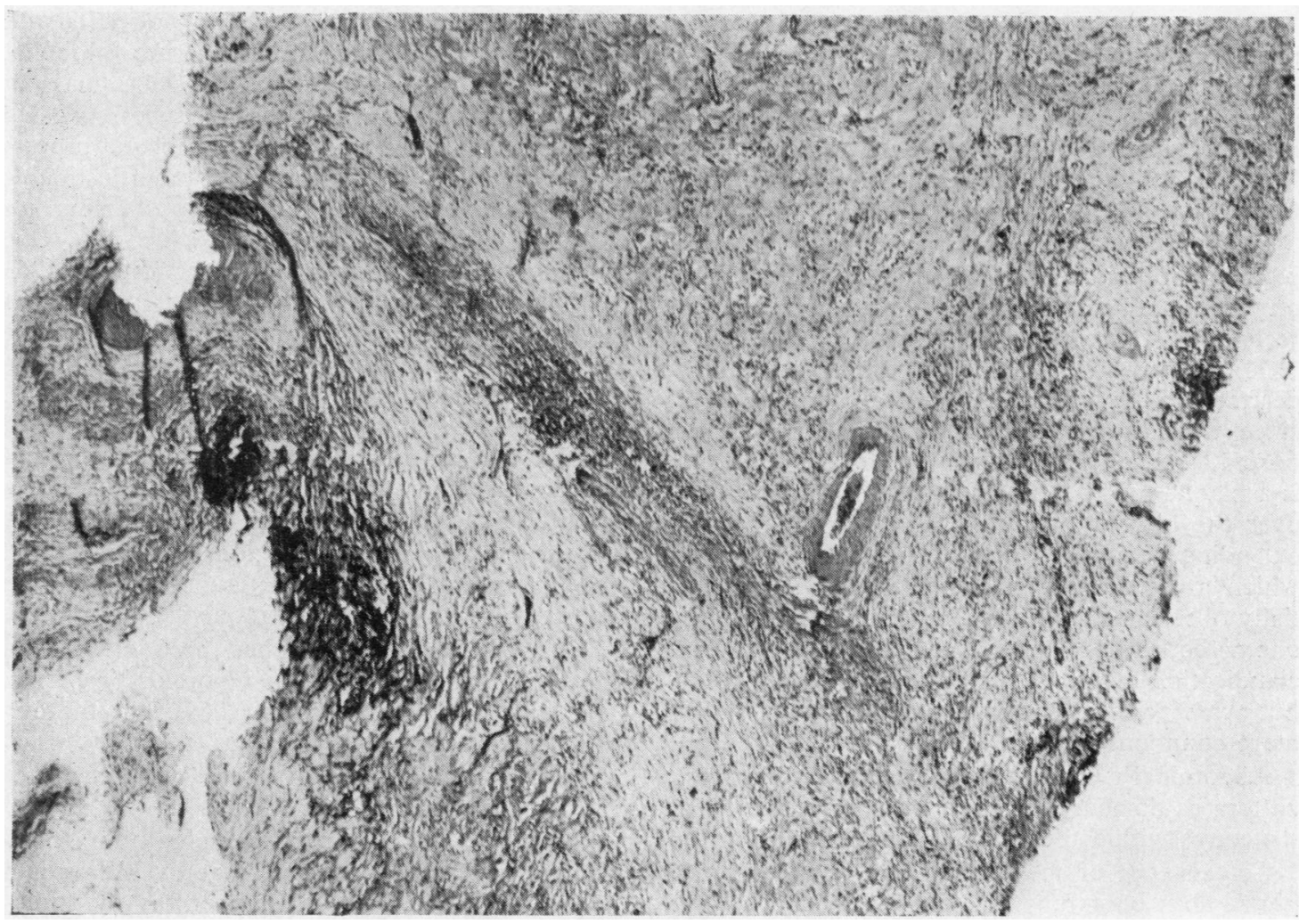

FIG. 4. Section of collagenous material removed from the superior mediastinum.

Subsequent renal function studies and a repeat intravenous pyelogram showed no change. The blood contained no C-reactive protein, antinuclear factor, thyroid, or gastric auto-antibodies.

There has been slight overall improvement in symptoms, but it is doubtful if treatment can be held responsible in the face of the natural development of a collateral circulation. On 31 October 1966 treatment was commenced with a combination of potassium $p$-aminobenzoate, $12 \mathrm{~g}$., and pyridoxine hydrochloride, $24 \mathrm{mg}$., (Potaba +6) per day in divided doses. If tolerance is maintained it is intended to continue this therapy for at least three months.

\section{DISCUSSION}

It could be argued that the case described fulfils the criteria of chronic mediastinal fibrosis but lacks the authority for retroperitoneal fibrosis in the absence of biopsy material despite laparotomy in 1958.

Nevertheless, the ever-growing literature on this disorder emphasizes the displacement and obstruc- tion of ureters associated with vague abdominal symptoms and eventual renal impairment.

Osler (1903) and Hume referred to superior vena caval obstruction due to chronic mediastinitis and quoted French writers as early as $\mathbf{1 8 5 6 .}$

Barrett (1958) quotes historical evidence that predates the first description to Hally, of Edinburgh, in 1848, or possibly to John Hunter in 1757.

Though separated by half a century, both authors stress the collateral venous drainage that can develop via the azygos and hemi-azygos systems, through the superior intercostal veins, internal mammary veins, and paravertebral system to the tributaries of the inferior vena cava.

The collateral circulation (venous return) is more adequate from the upper limbs than from the head and neck. Oedema of the hands, as in the case described, should indicate, therefore, that the obliterative process has spread downwards to envelop the azygos and hemi-azygos veins at their entry into the superior vena cava just above its junction with the pericardium (Tubbs, 1946). 
The large arteries, trachea, bronchi, and oesophagus are rarely obstructed (Hawk and Hazard, 1959), but it has been suggested that so-called idiopathic phrenic and recurrent laryngeal palsy may be due to this condition (Cameron, Ing, Boyle, and Mathews, 1961 ; Hache, Woolner, and Bernatz, 1962).

Ormond (1948) reported the first cases of 'idiopathic retroperitoneal fibrosis' in this country, and on the Continent 'la maladie d'Ormond' is still recognized (Nicolaesco, Bordeianu, and Felberg, 1966). However, a French urologist, Albarran, described a typical case in his textbook in 1902, since when more than 150 cases have been reported (Utz and Henry, 1966). The essential lesion is a plaque of dense fibrous tissue roughly centred over the bifurcation of the abdominal aorta and extending laterally to just beyond the ureters, which are pulled towards the mid-line and partially obstructed, with resultant hydronephrosis on one or both sides (Raper, 1956, 1960). Intermittent claudication may result from arterial compression, but evidence of inferior vena caval compression is more common.

Abdominal symptoms do not form a diagnostic pattern as do those resulting from compression of structures within the more rigid mediastinum.

Co-existence of mediastinal and retroperitoneal fibrosis has been reported in about a dozen cases (Morgan et al., 1966a ; Utz and Henry, 1966).

The true nature of the disorder is still in doubt, but many other fibrotic lesions have been considered to form a group of odd syndromes.

Pugh (1960) draws attention to the differences between localized collagenous deposits and generalized collagen disease. Quoting Barrett (1958), he divides the localized forms into two groups, first Peyronie's disease, Dupuytren's contracture, and keloid scars. Desmoid tumours could also be included here. The second group includes idiopathic mediastinal fibrosis, retroperitoneal fibrosis, pseudo-tumour of the orbit, and Riedel's thyroiditis. The syndrome known as 'de la Peyronie's disease' is well described by Ashworth (1960), but pathological changes in a testis have also been recorded (Cameron et al., 1961 ; Ardagh and Blake, 1964), including the case described here. Other examples of localized fibrotic lesions have been described more recently.

Livingstone, Lewis, Lynne Reid, and Jefferson (1964) questioned whether diffuse interstitial pulmonary fibrosis was a manifestation of collagen disorder, possibly an anarthritic form of rheumatoid arthritis. Que and Mandema (1964) report a case of idiopathic retroperitoneal fibrosis that presented as a systemic collagen disease with $\stackrel{\overrightarrow{\vec{S}}}{\stackrel{\vec{P}}{P}}$ Raynaud's phenomena, raised serum globulin, 을 ascites, antinuclear factor, and a dense mass at the right hilum. Lung function studies revealed $\frac{\bar{\rho}}{\sigma}$ reduced compliance and a diffuse fibrotic process $\stackrel{\mathbb{\complement}}{\varrho}$ of the lung parenchyma. It would seem justifiable to include interstitial pulmonary fibrosis or $\vec{\circ}$ sclerosing alveolitis in this list of disorders. One can enlarge the collection still further. In $1963 \vec{\omega}$ Bartholomew, Cain, Woolner, Utz, and Ferris $\stackrel{?}{\circ}$ described two cases of sclerosing cholangitis, one $\vec{x}$ associated with retroperitoneal fibrosis and the i other with Riedel's thyroiditis. Gravano, Begetti, iv and Iovine (1958) referred to the association of $\vec{v}$ chronic cholangitis with chronic pancreatitis and $\infty$ incorporated the term 'localized collagenosis' into 음 the title of their paper.

The aetiology of the condition is still in doubt. Not unnaturally, trauma, tuberculosis, and $\stackrel{\frac{5}{9}}{7}$ venereal disease have been frequently blamed.

Histoplasma capsulatum has been cited as a possible cause in five cases reported by Salyer, Harrison, Winn, and Taylor (1959), but the evidence was slender.

The case described here had a negative histoplasmin complement fixation test.

An attempt to explain the pathology on a post- $\stackrel{\mathbb{Q}}{\complement}$ inflammatory basis has been made by Milner and $\overrightarrow{\hat{O}}$ Mitchinson (1965). Their argument is that idio- 3 pathic retroperitoneal fibrosis and allied conditions are manifestations of a widespread disease - systemic idiopathic fibrosis-the result of healing inflammation of the adipose tissues.

Weber-Christian panniculitis is cited as the $\tilde{x}$ type example and systemic Weber-Christian $\frac{5}{3}$ disease as the more florid condition. There is much that is controversial in these papers, but reference to nodular vasculitis is interesting.

Many writers have favoured an auto-immune $\frac{}{5}$ hypothesis during the last 15 years, but factual $D$ assessment has not been encouraging. A report on a case of Riedel's thyroiditis and retro- $N$ peritoneal fibrosis by Turner-Warwick, Nabarro, and Doniach (1966) excluded any auto-immune $\mathcal{N}$ process, and four other cases of Riedel's thyroid- $\mathcal{\omega}$ itis examined since 1956 showed similar negative evidence. The case described here showed no evi- 0 dence of organ-specific auto-immune mechanisms. These authors quote Hardmeier and Hedinger + (1964), who question that Riedel's struma might $\frac{7}{T}$ be, primarily, an arteritic process comparable to $\frac{O}{\mathbb{D}}$ Takayasu's or 'pulseless' disease. They conclude by $\frac{\mathbb{Q}}{\mathbb{Q}}$ equating the fibrosis that appears in the soft tissues $\stackrel{\unrhd}{\unrhd}$ of the neck to a similar process that can occur in the mediastinum and retroperitoneum. 
Leaders in the Lancet $(1965,1966)$ have reminded us of iatrogenic retroperitoneal fibrosis. A leader in the British Medical Journal (1966) confirms this warning. Methysergide has been blamed but was unknown until retroperitoneal fibrosis had been recognized for at least a century. Graham (1964), being primarily interested in headaches, quotes Sicuteri, who first reported on this drug in 1959. It is a lysergic acid derivative and consequently shares the responsibility of other ergot alkaloids for their vascular effects. Several authors have recorded the association of retroperitoneal fibrosis with methysergide or other drug therapy, but cause and effect are not always apparent, e.g., Utz, Rooke, Spittell, and Bartholomew (1965), Parnes and Graham (1965), and Graham (1964). Although improvement has followed cessation of the drug in most cases, Schwartz and Dunea (1966) record no improvement in their case six months after withdrawal.

It would seem that some personal idiosyncrasy may exist and that all members of the ergot family are under suspicion. Utz and Henry (1966) support this view and refer to the interesting experimental evidence of a high incidence of neurofibromata found in animals intoxicated by ergot.

The appearance of cardiac murmurs and aortic valve disease has been noted in patients treated with methysergide (Graham, Suby, Le Compte, and Sadowsky, 1966), which reminds one of the occurrence of systemic lupus erythematosus during treatment by hydralazine or as a result of treatment by procainamide, and the rare occurrence of interstitial pulmonary fibrosis during treatment by methonium compounds. These strange drug reactions bear some resemblance to the effects of 5-hydroxytryptamine in that carcinoid syndromes tend to produce fibrosis of the lungs, the right heart valves, and a form of arteritis. These observations suggest that vasoconstriction and vasculitis may play some part in the causation of the localized collagenoses and emphasize the need for caution in the use of vasoconstrictor drugs.

Treatment by steroids has been recommended by a number of writers, but their results are not encouraging. The case described here showed slight improvement during treatment with prednisone over a period of nine months, but the development of a collateral circulation could have supplied the answer. Surgery may be life-saving when ureteral occlusion is advanced. Catheters can usually be passed and renal function restored prior to ureterolysis and intraperitoneal transplantation. When the upper mediastinum is involved decompression of the superior vena cava may be feasible but difficult; bypass surgery is less successful than when arteries are obstructed (Hache et al., 1962). The prolonged treatment of localized and systemic collagenosis by potassium $p$-aminobenzoate (Potaba) or a combination with pyridoxine hydrochloride (Potaba +6 ) has been reported by Zarafonetis (1964). This member of the vitamin B complex is said to increase oxygen uptake at tissue level and so interfere with the long-term effect of excess serotonin or diminished monoamine oxidase activity. The case described is now being observed during treatment with this preparation.

More recently, the action of Penicillamine on increasing the degree of soluble dermal collagen in rheumatoid arthritis and scleroderma has been reported by Harris and Sjoerdsma (1966). Confirmation of this work would be of interest regarding treatment of the case described.

Acknowledgements are gratefully extended to Dr. M. Ross and Dr. A. Craner for certain pathological and radiological assistance. Mr. J. Weaver, F.R.C.S., kindly performed the mediastinal biopsy with the assistance of Dr. L. H. Lithman, anaesthetist.

I am most indebted to Dr. J. B. Enticknap for the majority of the pathological investigations and for allowing me to combine his report on the biopsy specimens with that of Dr. H. W. Landells, who kindly examined the second specimen and also agreed this fusion. Dr. I. G. Murray, of the Mycological Reference Laboratory, London, W.C.1, performed the histoplasmin complement fixation test, for which I am most grateful.

My thanks also to Dr. D. Doniach, of the Middlesex Hospital, for the report of absence of autoantibodies.

\section{REFERENCES}

Ardagh, J. W.. and Blake, G. B. (1964). Idiopathic retroperitoneal fibrosis. N.Z. med. J.. 63, 362.

Ashworth, A. (1960). Peyronie's disease. Proc. roy. Soc. Med., 53, 692. Barrett,'N. R. (1958). Idiopathic mediastinal fibrosis. Brit. J. Surg., 46, 207.

Bartholomew, L. G., Cain, J. C., Woolner, L. B., Utz, D. C., and Ferris, D. O. (1963). Sclerosing cholangitis-its possible association with Riedel's struma and fibrous retroperitonitis. New Engl. J. Med., 269, 8.

British Medical Journal (1966). Leading; Article. Methysergide and retroperitoneal fibrosis. 1, 755 .

Cameion, D. G., Ing, S. T., Boyle, M., and Mathews, W. H. (1961). Idiopathic mediastinal and retroperitoneal fibrosis. Canad. med. Ass. J., 85, 227

Graham, J. R. (1964). Methysergide for prevention of headache. New Engl. J. Med., 270, 67.

- Suby, H. I., Le Compte, P. R., and Sadowsky, N. L. (1966). Fibrotic disorders associated with Methysergide therapy for headache. Ibid., 274, 359.

Gravano, L., Begetti, H., and Iovine, J. R. (1958). Coiangitis cronica estenosante $\mathrm{y}$ pancreatitis cronica recidivante: i expression de una colagenosis localizada? Pren. méd. argent., 45, 1613.

Hache, L., Woolner, L. B., and Bernatz, P. E. (1962). Idiopathic fibrous mediastinitis. Dis. Chest, $41,9$.

Hardmeier, T., and Hedinger, C. (1964). Is Riedel's struma prima rily a vascular disease? Virchow's Arch. path. Anat., 337, 547. 
Harris, E. D., and Sjoerdsma, A. (1966). Effect of Penicillamine on human collagen and its possible application to the treatment of scleroderma. Lancet, $2,996$.

Hawk, W. A., and Hazard, J. B. (1959). Sclerosing retroperitonitis and sclerosing mediastinitis. Amer. J. clin. Path., 32. 321.

Lancet (1965). Annotations. Methysergide and retroperitoneal fibrosis. 1, 1262.

(1966). Annotations. Drugs and retroperitoneal fibrosis. 1, 969.

Livingstone, J. L., Lewis, J. G., Reid, Lynne, and Jefferson, K. E. (1964). Diffuse interstitial pulmonary fibrosis. Quart. J. Med. 33, 71 .

Milner, R. D. G., and Mitchinson, M. J. (1965). Systemic WeberChristian disease. J. clin. Path., 18, 150-156.

Morgan, A. D., Loughridge, L. W., and Calne, R. Y. (1966a). Combined mediastinal and retroperitoneal fibrosis. Lancet, 1, 67. $1,603$.

Nicolaesco, T., Bordeianu, A., and Felberg, B. (1966). La maladie d'Ormond (fibrose rétroperitonéale idiopathique). Gastroenterologia (Basel), 105, 205.

Ormond, J. K. (1948). Bilateral ureteral obstruction due to envelopement and compression by an inflammatory retroperitoneal process. J. Urol. (Baltimore), 59, 1072.

Osler. W. (1903). On obliteration of the superior vena cava. Bull. Johns Hopk. Hosp., 14, 169.

Parnes, L. R., and Graham, J. R. (1965). Headache rounds, No. 36.
Pugh, R. C. B. (1960). The pathology of fibrotic lesions. Proc. rov:. Soc. Med., 53, 685 .

Que, G. S., and Mandema, E. (1964). A case of idiopathic retroperitoneal fibrosis presenting as a systemic collagen disease. Amer. J. Med., 36, 320.

Raper, F. P. (1956). Idiopathic retroperitoneal fibrosis involving the ureters. Brit. J. Urol., 28, 436.

(1960). Idiopathic retroperitoneal fibrosis involving the ureters. Proc. roy. Soc. Med., 53, 690.

Salyer, J. M., Harrison, H. N., Winn, D. F., and Taylor, R. R. (1959) Chronic fibrous mediastinitis and superior vena caval obstruction due to histoplasmosis. Dis. Chest, 35, 364.

Schwartz, F. D., and Dunea, G. (1966). Progression of retroperitoneal fibrosis despite cessation of treatment with methysergide. Lancet. $1,955$.

Tubbs, O. S. (1946) Superior vena caval obstruction due to chronic mediastinitis. Thorax, 1, 247.

Turner-Warwick, R., Nabarro, J. D. N., and Doniach, D. (1966) Riedel's thyroiditis and retroperitoneal fibrosis. Proc. roy. Soc. Med., 59, 596.

Utz, D. C., and Henry, J. D. (1966). Retroperitoneal fibrosis. Med Clin. N. Amer., 50, 1091.

- Rooke, E. D., Spittell, J. A., and Bartholomew, L. G. (1965) Retroperitoneal fibrosis in patients taking methysergide. $J$. Amer. med. Ass., 191, 983.

Zarafonetis, C. J. D. (1964). Antifibrotic therapy with Potaba. Amer. J. med. Sci., 248, 550 . 